\title{
La historia comparada como posible metodología para comprender los movimientos sociales del magisterio en Brasil y Colombia, entre 1954-1990
}

\author{
The comparative history as possible methodology \\ for understanding social movements of the teachers \\ in Brazil and Colombia, among 1954-1990
}

\section{Resumen}

El presente artículo expone el proceso histórico y conceptual de los diferentes desarrollos de las historias comparadas: la historia transnacional, la historia cruzada y la asimétrica. En primera instancia se abordará la pertinencia y potencial analítico de estos enfoques metodológicos; en segundo lugar se trabajará la conceptualización de la Historia Trasnacional y Cruzada desde su emergencia y metodología, algunos de sus exponentes más importantes y una breve presentación del debate alrededor de una Historia Comparada sistemática, diferente de la Historia Cruzada (croisse), y su lugar frente a la historia trasnacional o asimétrica, así como sus posibilidades de realización; finalmente, se pretende ver encuentros y contingencias al encauzar la historia trasnacional asimétrica en la comprensión y explicación de los movimientos sociales en el contexto del siglo XX.

Palabras clave: Historia Comparada, Historia Cruzada, Historia Trasnacional, Historia Sistemática, movimientos sociales, Movimiento Sin Tierra, Movimiento Pedagógico.

\section{Abstract}

This paper presents the historical and conceptual process of the different developments of comparative histories: transnational history, history cross and asymmetric. Firstly, the relevance and analytical potential of these methodological approaches will be addressed. Secondly the conceptualization of Transnational and Cross History and will be studied from their emergence and methodology, some of its most important exponents and a brief presentation of the debate about a systematic, different Comparative History of the Cross History ( Croisse ) and its position in regards to transnational or asymmetrical history, as well as their chances of realization. Finally, this work aims to see meetings and contingencies when channeling the asymmetrical transnational history in understanding and explaining social movements in the context of the twentieth century.

Keywords : Comparative History, History Crusade Transnational History, History Systematics, social movements Landless Movement, teaching movement.

\footnotetext{
1 - Este escrito es una introducción preliminar para el proyecto de Tesis del Doctorado en Historia de la Universidad Nacional de Colombia, sede Bogotá. Se escribió, durante el primer semestre de 2013 y corresponde al trabajo final del curso Historia Comparada II dirigido por la Doctora Gisela Cramer docente del Departamento de Historia de la UN. El trabajo fue entregado el día 15 de mayo de 2013 . Corregido y ajustado el 29 de agosto de 2013.
} 


\section{Historia y comparación histórica}

La "comparación" ha sido un concepto poco abordado por los historiadores, pero muy útil para investigadores de las ciencias sociales, especialmente sociólogos, politólogos, economistas y antropólogos, pues les ha permitido darle un uso más cercano a sus metodologías y evitar marcos de explicación reducidos, específicamente en el abordaje de historias nacionales; la posibilidad de tener una visión más amplia hizo que sus análisis traspasaran las fronteras de los objetos de estudio y de los enfoques utilizados para, como afirma Kocka (2002), "evitar el provincialismo".

Así, los beneficios del enfoque comparativo para los historiadores incluyen, no solo la posibilidad de salir de los marcos espaciales y temporales predeterminados, individuales y/o locales, sino ampliar las perspectivas de análisis, para alcanzar los objetivos de interpretación o de comprensión que desde el ámbito meramente nacional no son posibles o resultan reducidos. Por ello resulta más que pertinente el objetivo del presente texto: justificar y ampliar las afirmaciones presentadas y dar cuenta de cómo funcionan las metodologías de las historias comparadas, especialmente en la historia trasnacional, que es con la que me identifico.

Siguiendo la metodología de la historia trasnacional (integrada al cuerpo de la historia comparada), y a manera de ejemplo, tomaré el desarrollo de los movimientos sociales europeos de 1968, para proponer algunas implicaciones de los métodos y sentidos empleados en la investigación ${ }^{2}$. No se desarrollará un trabajo comparativo, sino que se esbozará a la luz de una propuesta y se presentarán los diversos enfoques de la Historia Comparada, cruzada y transnacional. Por tanto, algunas preguntas que podrían ser pertinentes son: ¿Es posible estudiar los movimientos sociales desde la historia trasnacional?; ¿hay implicaciones mutuas en el surgimiento de movimientos sociales de dos lugares distintos?; ies posible encontrar intercambios de fines y medios en el desarrollo histórico de los repertorios de protesta y organización colectiva de los movimientos sociales? Si es así ¿qué elementos han permitido el intercambio cultural para definir la identidad, aparición y desarrollo de la protesta en nuestro país?; ¿hubo manejo y traslado de información entre países?; ¿ cómo llegó la información, qué vehículos la permitieron?; ¿fue pertinente?; ¿qué efectos produjo en los países?

\section{Pertinencia y potencial analítico de los enfoques comparativos}

Desde la antigüedad la comparación ha estado presente en la investigación histórica, pero cobró importancia, especialmente desde la sociología, en la configuración de la historia moderna y de las ciencias sociales del siglo XIX; Tocqueville, Marx y Weber introdujeron categorías analíticas para estudiar las sociedades desde procesos como cambio y explicación, logrando un profundo conocimiento a partir de conceptos históricos diferentes a los de su época, tales como progreso y finalidad, para referirse a al individuo en términos de estar sujeto a la fatalidad, o para definir un algo ajeno a la voluntad que explicaría la forma en que desde el colectivo se definió la forma en que algunos jugaron un papel importante como sujetos históricos. Al construir y definir constantes que podrían ser causalidades fijas de explicación histórica, encontraron posibilidades más amplias y diferentes de comprensión, iniciando el camino de la historia moderna y su encuentro con las ciencias sociales.

A comienzos del siglo XX la historia incluyó, especialmente desde la escuela de los Annales, los métodos de las ciencias sociales (sociología, economía y geografía) y el análisis social y económico desde perspectivas amplias. La interdisciplinariedad y la comparación fueron cardinales para la explicación histórica, pues permitieron trasformar e incorporar análisis de los acontecimientos simples, cambiando las explicaciones nacionales por grandes estructuras al interior de las sociedades que, especialmente desde lo económico y social, facilitaron comparaciones con otras sociedades y la comprensión de sus cambios, permanencias, similitudes y diferencias.

A comienzos del siglo XX Marc Bloch (1886-1944), referente de la escuela de los Annales y de la comparación, se esforzó por precisar que la historia no puede ceñirse a las fronteras nacionales y buscó temas cuya explicación desbordara lo local, para lo cual consideró necesario articular lo nacional con el trasfondo de otros lugares. En este orden, durante el Congreso Internacional de Ciencias Históricas (1930) al afirmar que las explicaciones de tipo nacional pueden llevar al error de considerar los hechos históricos como algo excepcional, apuntaló la comparación como una posibilidad que permite modificar lo familiar, dejando además de lado su carácter de originalidad, lo cual llevaría al historiador hacia un extrañamiento que aumentará su interés por comprender los intercambios; esto implicaría comparar dos fenómenos sociales o sociedades, vecinas y contemporáneas (condiciones necesarias), empleando series, curvas evolutivas y demás datos relevantes en la tarea de localizar diferencias y similitudes (Bloch, 1995, p. 115).

Dicha visión es la que podemos definir como sistemática, porque aplica por igual la comparación metodológica en las sociedades a estudiar, para encontrar influencias $\mathrm{y} / \mathrm{o}$ causalidades similares $\mathrm{y} / \mathrm{o}$ diferentes en ellas, e interpretar y comprender esos encuentros. Según Bloch, la idea es hallar expresiones históricas evidentes, tales como el origen de las instituciones, sus variaciones en el tiempo y su influencia en otros; estos fenómenos no se pueden comprender por sí solos, ya

2 - "1968 in Europa". (Klimke \& Joachim Sharloth, 2008). 
que en otras circunstancias no se habrían manifestado en alguna de las sociedades estudiadas. Las comparaciones no se pueden abordar por separado, pues su estudio conjunto es el que permite comprender y hacer evidente la existencia de "relaciones muy antiguas entre sociedades diferentes" (Bloch, 1995, pág. 114), mientras rompe los límites nacionales y facilita una síntesis más comprensible, ampliando la visión de las realidades sociales que estaban "encerradas en compartimientos topográficos" $(\mathrm{p}, 141)$.

Es en este sentido que tiene relevancia el llamado de Bloch a que los historiadores se apropien del método comparado que atraviesa los estudios políticos y económicos; su pertinencia radica en que admite una comprensión de lo percibido como diferente, contribuyendo a la posibilidad de medir la originalidad de los sistemas sociales. A pesar de ello, Bloch advierte que el método de comparación no es del todo poderoso, ya que resulta más dispendioso y lento que las investigaciones regionales o nacionales, pues para llegar a los análisis, se debe utilizar la síntesis, lo cual implica la obligación de leer lo publicado con anterioridad, no solo del lugar, sino de regiones más lejanas, para comprender las causas más allá de lo local y lo específico.

Por otra parte, el método comparativo también debe su lugar en los estudios de la historia al trabajo realizado por Jürgen Kocka (1941), discípulo de la escuela de Bielefeld y representante de la Nueva Historia Social Alemana, importante en las décadas del 60 y $70^{3}$ por sus estudios de la historia de los trabajadores de las grandes empresas alemanas, europeas y de Estados Unidos. Tomó los métodos de Ernest Labrousse y analizó los procesos sociales de la sociedad alemana desde la perspectiva de la modernización, la industrialización y orígenes de la Europa moderna; desarrolló el experimento indirecto, cuya función es establecer causalidades desde el análisis y la descripción para facilitar una perspectiva paradigmática. El uso de preguntas directrices le permitió encontrar las semejanzas y diferencias de dos o más fenómenos históricos; la pregunta inicial es central en su planteamiento, pues permite generar el efecto de extrañamiento y abrir la visión a situaciones diferentes $y$ provincianas.

Al estudiar la historia de varios lugares desde conceptos generales (que pueden no ser cercanos en el espacio o el tiempo), Kocka provoca una reflexión sobre las nociones y sobre la precisión de las preguntas relevantes que permiten determinar las diferencias. Las similitudes -afirma- serán producto de la acción humana en su desarrollo en los lugares comparados, por ello es necesario elegir unidades de comparación de tiempo, datos y debates nacionales o internacionales, que deben tener elementos comunes en los lugares a investigar y ser susceptibles de ser aisladas para su comparación, permitiendo así encontrar similitudes o diferencias con el fin de poderlas explicar.
Sin embargo, establecer causalidades implica un problema de "ceteris paribus" (igualdad de condiciones), ya que en la realidad no existen sociedades exactamente iguales. El uso de esta metodología no garantiza una cadena de causalidades iguales, pues, como se advirtió, de ningún modo encontraremos dos o más sociedades con elementos uniformes. La búsqueda de aspectos similares, estableciendo diferencias y similitudes, depende de la pregunta que se haga al momento de abordar la investigación. La comparación se configura a través de la formulación de preguntas bien definidas, pues los fenómenos solo pueden ser comparados en relación a algo o a un tercero, con conceptos claros, nítidos, ya que solo con su ayuda es posible ponerlos en contexto.

Desde la misma perspectiva encontramos a James Mahoney y Dietrich Rueschemeyer, quienes también abordan la Historia Comparada, pero desde la Historia Comparada y Sistemática. Argumentan que, aunque es esencial para explicar procesos macro-sociales, no permite establecer una teoría general sobre el cambio social; por ello se interesan en ella desde su utilidad para entender los procesos de modernización, que difiere de lo propuesto por la sociología histórica y el institucionalismo histórico; el auge de la Historia Comparada (HC) entre los años 1970 y 1980 es, desde su perspectiva, diferente al uso que le dan estas disciplinas, porque su reavivamiento se ha centrado en el estudio de la formación histórica del Estado y su reestructuración, el desarrollo económico y la política industrial en Europa, América, África y Asia. Por ello la $\mathrm{HC}$ ha permitido entender las relaciones raciales y étnicas en las identidades nacionales, el género (derechos a la mujer), la aparición de la democracia y el autoritarismo, pues se centra en las "preguntas grandes".

Mahoney y Rueschemeyer establecen tres características para una posible implementación de la Historia comparada: 1) El propósito principal estriba en identificar las causalidades, aislar factores con los cuales asumir el efecto causal; 2) El análisis comparativo en sí mismo debe establecer un proceso; 3) La comparación debe estar en un contexto, de tal manera que se puedan observar todos los aspectos similares y los contrastes. Así, si el contexto es fundamental, este es el escenario en el cual se desenvuelve el historiador para hacer su análisis, que debe estar delimitado (época, lenguaje, cultura), por las grandes trasformaciones sociales y de clase: el nacimiento del fascismo, del franquismo, del genocidio o los sistemas de esclavitud, etc. Es desde esta perspectiva que Barrington Moore analizó las distintas sendas hacia la modernidad, tomando los casos de Inglaterra, Francia, Estados Unidos, China, Japón e India y combinando la descripción, el análisis de las condiciones y la interpretación de las consecuencias en diferentes procesos.

Así, desde su apuesta, la Historia Comparada Sistemática (HCS) debe realizarse con dos o más

3 - La Escuela se hizo importante por su trabajo a favor de la renovación histórica y por vincular la historia a las ciencias sociales (sociología especialmente); no desarrolló propiamente una historia marxista, pero sí la abordó, concentrándose en Max Weber. 
sociedades que al menos compartan ciertas analogías o diferencias, para desde allí comprender influencias mutuas, filiaciones y supervivencias, o también permite empezar nuevas investigaciones que expliquen algo que no era posible comprender desde lo nacional; las conclusiones y aplicaciones analíticas deben llevarse a cabo de la misma forma para todas las sociedades o lugares estudiados, y la credibilidad de la comparación depende de que ésta aborde lugares, países, que cuenten con una gran bibliografía, pues el trabajo no se compromete solo con las fuentes primarias.

Para finalizar, es conveniente anotar que la comparación ha influido en las formas de hacer de los historiadores desde sus inicios disciplinarios, la cuestión es que se ha realizado de forma poco sistemática y por lo general de manera implícita y poco evidente; Al respecto, Kocka afirma y la define como historia comparada asimétrica, desde donde es posible que abordar lo nacional con fuentes primarias y lo externo con secundarias. A continuación se trabajará este concepto, junto a la comparación cruzada y transnacional.

\section{Comparación asimétrica, cruzada y trasnacional}

Para definir la Historia Trasnacional (HT) y Cruzada (Coisse), así como el concepto de reflexividad y comparación asimétrica, se tomarán como referencias a Michael Werner, Benédicte Zimmermann y Jurgen Kocka. En principio, es importante anotar que el enfoque de la Historia Trasnacional es una reconfiguración reciente; su desarrollo se postula como una forma de enmendar o ayudar a la Historia Comparada (HC), entendiendo las debilidades analíticas que le impiden trabajar lo cruzado o enredado (historia cruzada), las cuales le llevan a frenar o esconder los avances de la historia como tal; Kocka (2003) entiende estas dificultades y las explica a partir de los siguiente puntos ${ }^{4}$ :

1. Uso de fuentes secundarias. La mayoría de los estudios comparativos dependen fuertemente de la literatura secundaria o de las fuentes secundarias, por ello resulta más difícil obtener las fuentes de un mismo lugar y leerlas en su idioma original, lo cual representa un serio problema, ya que las fuentes y el dominio de la lengua son fundamentales para la erudición histórica moderna.

2. Unidades de comparación. El enfoque comparativo supone que las unidades de comparación pueden ser apartadas unas de otras. Ni la continuidad entre dos fenómenos, ni sus influencias mutuas les constituyen como casos de comparación; más bien son casos independientes que se reúnen analíticamente mientras demandan similitudes y diferencias entre sí. En otras palabras, la comparación sistemática rompe las continuidades, los cortes o enredos, e interrumpe el flujo de la narración; llama a la reconstrucción de las continuidades y a enfatizar en la interdependencia, así como en las formas narrativas de presentación, que son elementos clásicos de la historia como disciplina.

3. Totalidades. Para la Historia Comparada es difícil contrastar totalidades, en el sentido de las individualidades completamente desarrolladas; más bien confronta algunos aspectos. Por lo tanto, es fundamental decidir qué puntos de vista se desea comparar, desde preguntas específicas o intereses cognitivos (Erkenntnisinteressen) que trabajarán dos o más casos; incluir más de dos asuntos significa un mayor cuidado en cuanto a la decisión selectiva sobre los puntos de vista, preguntas y problemas que se quieren comparar. En otras palabras, la comparación implica un grado de selección, abstracción y des-contextualización.

Las razones mencionadas por Kocka abogan por el desarrollo de historias cruzadas o trasnacionales, que al final permitan comprender mejor los méritos de la comparación. Es desde esta perspectiva que se hace posible entender que la reflexividad ${ }^{5}$ sea uno de los elementos más sobresalientes para Werner y Zimmermann (vinculada de cierta manera con el posmodernismo); de hecho, desde lo histórico o lo cultural en las Ciencias Sociales, este fenómeno reflexivo ha producido certeros cambios que han permitido configurar giros trascendentales que trasgreden el estudio tradicional en las disciplinas sociales. Según Werner y Zimmermann lo reflexivo es una nueva mirada en esta práctica investigativa, la cual responde a los cambios sociales significativos que se dieron luego de las transformaciones culturales y políticas de 1989 , desde la caída del Muro de Berlín, como la cuestión de la aldea global contemporánea (globalización) o la multipolaridad, entre otras.

Estas nuevas prácticas académicas permiten analizar introspectivamente el fenómeno social y cuestionan la uniformidad de las categorías comparativas sistemáticas, que ya no se conciben sobre procesos sino a partir de conceptualizar las cosas específicamente. Las categorías no deben pensarse como algo natural, sino como socialmente construidas: en vez analizar "pobreza" desde una perspectiva reflexiva, es más oportuno conceptualizarla como categoría de análisis. En últimas, tales clasificaciones pueden considerarse como una concepción posmodernista y una nueva organización epistemológica que lleva a re-significar el objeto de investigación, los marcos de referencia y la inducción pragmática. La historia cruzada, en este sentido, hace énfasis en dichos elementos, pues también toma reflexiones de la historia comparada e intenta trascender la historia nacional.

A ello se suma el énfasis de historia cruzada en la reflexividad, producto del giro cultural y lingüístico,

4 - La traducción es propia.

5 -Es una acción del investigador que le permite entender lo que pasa en un lugar, es fundamental que pueda reflexionar sobre lo que sucede en todos los lugares estudiados y en las categorías que emplea; primero sobre el objeto, segundo sobre los actores y tercero sobre las categorías de análisis. 
como concepción que explica las categorías conducentes a la sensibilidad sobre el objeto de investigación. Por tanto, ella nace bajo la perspectiva de los giros historiográficos y de la fragmentación del conocimiento de las Ciencias sociales a finales del siglo XX; $\mathrm{y}$ es en este orden de ideas que, más que observar grandes procesos, se suele concentrar en problemas focales a través de transferencias (elementos que van de un lugar a otro en ambas direcciones), las cuales se pueden analizar desde las categorías de diacronía o sincronía.

En este sentido, Werner y Zimmermann insisten en que muchos fenómenos trascendentales no se prestan para ser analizados con la metodología de la historia comparada, sino que requieren además una mirada de la historia cruzada, pues no existen aisladamente, sino que implican una intersección e influencia de causalidades entre los casos y elementos comparativamente similares en el desenvolvimiento de los procesos. Como ejemplo, plantean el fascismo rumano, pues sería muy difícil analizar su surgimiento sin considerar la cercanía e influencia del fascismo en Italia y Alemania. Así, y acercándose a mi objeto de investigación, también discuten el fenómeno de las movilizaciones de 1968, la forma en que los sucesos de aquel mayo francés se desencadenaron en varios puntos de Europa y otras partes del mundo, y cómo surgieron de intercambios y transferencias entre grupos de jóvenes de varios países; fenómenos como este parten del intercambio de fuerzas que se influyen en los resultados.

El análisis en el enfoque comparativo de transferencias, cruzado o enredado, vincula igualmente movimientos socioculturales concretos, en los que pueden existir cruces y desviaciones, donde la reflexividad es capaz de permitir pensar y conceptualizar la manifestación desde la perspectiva del investigador a un nivel fenomenológico, para lo cual se puede tener en cuenta:

- El impacto del giro (hermenéutico) cultural y lingüístico en la reflexión sobre las categorías.

- La distinción de la historia comparada frente a la historia cruzada, la cual es vista como más interactiva.

- Los intercambios e influencias de otras disciplinas sociales a nivel conceptual y fenomenológico.

- La reducción en la escala del objeto de investigación, ahora orientado a problemas menos trascendentales que los de la Historia Cruzada.

Así, para esta historia de transferencias cruzadas es pertinente ver un determinado fenómeno reduciendo su escala, tanto en su organización y procesos, como en la transmutación de sus configuraciones internas; ejemplo de ello es la implementación de los modelos pedagógicos en Colombia, que en ocasiones no presentó cambios y se mantuvo estática frente a su fase formativa tradicional con respecto al modelo originario, mientras en otros momentos presentó cambios arrolladores, especialmente en las décadas de 1970 y 1980 con la Pedagogía Popular que provenía del Brasil. Ello puede explicar que tales variaciones no son guiadas necesariamente por un poder central, sino que parten de las interacciones sociales y culturales en los grupos humanos y en un contexto determinado. Lo mismo sucede con la legislación mundial sobre los derechos LGBTI, la cual no hace parte de una política supranacional dirigida, sino que se da a partir de las transferencias y fuerzas domésticas o locales, muchas veces desligadas del poder. Así, el concepto de transferencia parece más pertinente cuando no hay pretensión de poder en la transmisión; aunque esta acción (del poder central) puede ser explícita en algunas ocasiones, ello no daría la posibilidad de explicar o conceptualizar algún elemento en particular.

Es en este orden de ideas puede establecerse que la historia comparada permite comprender y precisar las características generales (externas) del objeto a tratar, mientras que la historia cruzada o trasnacional lo analiza en sus particularidades puntuales (internas). Finalmente, si el método de la historia comparada es rígido y sistemático, la historia cruzada permite utilizar metodologías menos rigurosas y más cualitativas. A pesar de ello, las dos formas de hacer historia se relacionan en cuanto a que los actores sociales son agenciados, es decir, en la forma en que se aborda el sujeto en el fenómeno y en sus posibilidades de acción, no reducidas solo a la estructura. Frente al tema de la escala, se puede concluir que lo trasnacional tiene que ver un poco más con el uso de fuentes primarias, sin darle mucho peso a la comparación.

En este sentido, las comparaciones asimétricas planteadas por Kocka, al permitir analizar el interior de un fenómeno con fuentes primarias y su exterior con fuentes secundarias, facilitan comprender el alrededor de la región. Sin embargo, estos autores al hacer un llamado a mantener la comparación rigurosa, a no ignorar o descuidar las interrelaciones entre los casos a comparar, y a analizar sus diferencias y similitudes, nos invitan a no perder de vista la forma en que se percibe y se ven afectados entre sí en ambos lados de la ecuación. Concluyendo, para este tipo de comparaciones no es necesario elegir entre una historia comparada o cruzada, el objetivo es llegar a combinarlas.

\section{Movimientos sociales del magisterio en Colombia y Brasil (1954-1990) desde la historia trasnacional. Una propuesta}

Las posibilidades de uso y de la combinación de estas historias se enmarcaran en los debates en torno a la Nueva Historia Trasnacional desde las propuestas de Micol Seigel (2009) en su trabajo Encuentros desiguales $^{6}$. La autora define una Historia Transnacional 
que implica ver lo comparativo desde una perspectiva distinta de la tradicional: a partir de la inclusión de los procesos de formación del sujeto, que cuestionan de entrada la llamada neutralidad en los procesos de comparación sistemática, planteando que su desarrollo no permite expresar el poder o los poderes de configuración del sujeto en las sociedades estudiadas. La transnacionalización le ha permitido ver, en y desde la segunda posguerra, el colonialismo y el surgimiento de diversas resistencias y movilidades sociales en las luchas anti-coloniales y pos anti-coloniales. La influencia de Franz Fanon en su propuesta sobre resistencia y alteridad (ver los condenados de la tierra), le ha permitido plantear la búsqueda comparativa de identidades propias en sus resistencias con un gran potencial analítico.

Así, para Seigel la historia comparada no es ni ha sido trasnacional, sino internacional. Además de disminuir los excepcionalismos y provincialismos, los estudios trasnacionales han permitido encontrar un marcado eurocentrismo que ha invisibilizado los juegos de poder en este tipo de historias, y hacen evidente la necesidad de emplear enfoques más amplios para comprender fenómenos como por ejemplo el movimiento de 1968, que demandan miradas más profundas y destacan otras problemáticas, relacionadas con los estudios simbólicos, emotivos 0 cognitivos y, lo más importante, con la configuración del sujeto en su lucha contra el Estado y las formas de conocimiento que lo negaban, lo cual se vincula con la organización de grupos sociales fuera de las afiliaciones nacionales.

Para este enfoque, afirma, es importante comprender los significados de cada símbolo o contexto cultural y su desarrollo histórico, incluso desde el sentido del autor que escribe; la actitud reflexiva es fundamental para entender el significado de los símbolos y expresiones culturales usados en las relaciones de cada lugar, llevando a la pregunta por ¿Cómo hacer entonces esta comparación? En primer lugar, la tarea del comparativista debe estar redefinida desde la relación e interacción mutua de los temas investigados; en segundo lugar, Seigel considera, retomando los debates planteados por Kocka, que metodológicamente no es conveniente aislar algunos elementos fuera del contexto para hacerlos comparables, ya que esto perjudica el entendimiento de los fenómenos, pues impide indagar sobre la noción de sujeto en cada lugar comparado, descuidando la particularidad.

Para enfrentar las posibilidades de enfocar esta historia en los movimientos sociales, con el método asimétrico, y explicarla o ampliarla, tomaré como referencia a Klimke y Joachim (2008), quienes hacen una contribución al estudio de la historia moderna en un marco transnacional, concentrándose en "1968", año que simboliza los movimientos de protesta en muchas partes de Europa; para ellos estos momentos marcaron un punto de separación de dos mundos: el primero definido principalmente por las naciones soberanas y las grandes potencias; $y$ el segundo determinado por el alcance de la influencia del movimiento en los países más pequeños, ambos motivados tanto por fuerzas no nacionales, globales y/o transnacionales, como por las agendas geopolíticas y nacionales (p, vii).

Tal perspectiva demuestra que "1968" fue un fenómeno transnacional, no solo europeo, que llegó a cubrir Oriente y Occidente; la "revolución" tomó muchas formas y diversos grados de intensidad en distintos países, desde donde tuvo un impacto casi inmediato en lugares fuera de Europa, como China, EUA y el continente americano. Los "revolucionarios" fueron conscientes de su papel como jugadores en sus fronteras nacionales y en el escenario mundial. Aunque Klimke y Joachim se concentran en Europa, también anotan el impacto evidente de "1968" en Estados Unidos, China y otros países, planteando la forma en que la Nueva Izquierda ( New Left), diferenciándose de la vieja izquierda, cuestionó la supuesta omnipotencia de la nación y el Estado, debatiendo su privilegio (desde la llamada comunidad nacional y autoridad del Estado) como definidores y reguladores de los seres humanos. Para estos "radicales" lo nacional o estatal fue la principal fuente de identidad en su enfrentamiento, pues consideraban que dichas figuras eran demasiado restrictivas para los derechos individuales y del movimiento social.

En este marco, los estudios que se realicen sobre los movimientos y movilizaciones del Magisterio en Brasil y Colombia, entre 1954 y 1990, desde los enfoques comparados, pueden buscar plantear formas para comprender la experiencia y la costumbre, antes que las definiciones de tipo político, como elementos vitales en su surgimiento y su desarrollo, sobre la base de expresiones afines a lo que el sociólogo Raúl Zibechi (2006) define como poderes antiestatales que buscan organizarse a partir de los análisis sobre la forma en que opera la comunidad. Todo, considerando, junto Melucci (1999), que aunque el pasado sea el punto de partida, estos movimientos no son un objeto empírico o unitario que pueda ser investigado aisladamente; su análisis implica el concepto de construcción de la identidad colectiva y la complejidad que supone, al ser interactivo $y$ negociado entre los sujetos que participan de la acción, sobre la base de estudios de los sujetos.

Así, el estudio de los movimientos sociales del magisterio en Brasil y Colombia, y de su acción colectiva, puede también buscar relacionar las luchas iniciadas durante la dictadura militar ${ }^{7}$ en Brasil (1964-1985) y Colombia (1953-1957), y en el restablecimiento de la "democracia" en ambos países, que llevó a la creación de la mayoría de grupos y movimientos sociales y

7 - Luego de un breve paso por el caricaturesco régimen parlamentario y por el intento de los presidentes Janio Quadros y Joao Gulart de vincularse a las economías comunistas, y de plantear el debate norte-sur, desplazando el oriente-occidente de la guerra fría asumido por toda la región (1961-1964) 
civiles, muchos de ellos conformados por educadores, que en ambos lugares se opusieron a la figura estatal o a la dictadura y las denunciaron por violar los Derechos Humanos, a partir de la configuración de organizaciones y de generar nuevas movilizaciones y repertorios de lucha que, desde la figura de la historia trasnacional, se enfrentaron al poder partiendo de manifestaciones simbólicas y emotivas, pero que movilizaban propuestas cognitivas y pedagógicas de gran envergadura que influyeron en la configuración del sujeto en su lucha contra el Estado y las formas de gobierno autoritarias.

Lejos de presentar una mirada estructural, se busca indagar por la configuración del Movimiento Educativo que lideró Paulo Freire en Brasil (1950), el cual estuvo vinculado a la Teología de la Liberación y que a la postre convergió con el Movimiento Sin Tierra (Sem Terra) de los años 1980 y con el proceso antiglobalización que se dio desde allí al despuntar el siglo XXI. Por su parte, en Colombia se podría observar la aparición de las primeras estructuras sociales y gremiales del magisterio ${ }^{8}$ con una configuración diferente, pues ya no tenían una base de egresados normalistas, sino de universidades, y fue así como lograron su vínculo con otros movimientos y con las expresiones políticas y sociales propias de estos lugares, para luego coincidir en la creación de un Movimiento Pedagógico en los años 1980 y su proyección hasta la Constitución de 1991 y la promulgación de una Ley general de educación en 1994. Todo giraría alrededor de la posibilidad de encontrar nuevas opciones interpretativas desde la intersección de las características de los dos países, de tal manera que se pueda explicar el despertar de las formas internas de la vida colectiva que se expresaron en sindicatos y movilizaciones sociales de protesta, las cuales posteriormente se instauraron en las movilizaciones y los movimientos del magisterio colombiano y, por efectos internos, se recompusieron en las formas de vida, y en la organización, producción y reproducción de territorios y simbologías propias de su ser cotidiano, que no buscaron incorporarse en su interior, sino su alternatividad (Zibechi, 2003).

Para el caso del Brasil y Colombia la comparación trasnacional permitiría integrar los movimientos desde su emergencia hasta sus posibles encuentros y desencuentros; en los dos países convergen Comunidades Eclesiales de Base (CEB's), las cuales están vinculadas a la teología de la liberación que, junto al planteamiento del mestizaje y las campañas educativas y de formación política, consolidó la potencia de los movimientos Sin Tierra (MST) en Brasil, y del Movimiento Pedagógico en Colombia, cuyos procesos y fines fueron igualmente disímiles. Esta continuidad toma diferentes rumbos, pues los Movimientos Sin Tierra (MST) de Brasil lograron destituir un presidente en los años 1990, frenar las privatizaciones y presionar hasta a instaurar un gobierno progresista (de izquierda), forzando a las élites a escuchar e implementar sus demandas sociales, las cuales implicaron necesidades de un orden distinto al establecido desde el Estado; mientras que el Movimiento Pedagógico (MP) de Colombia logró repercusiones nacionales (1985-1990), pero terminó concentrado en lo local, expresándose al parecer exclusivamente en la Alcaldía de Bogotá y consiguiendo reformas muy restringidas de tipo político y educativo en Bogotá y en el resto del país.

En Brasil las movilizaciones, desde la misma implantación de la republica en 1898, pasando por el movimiento tenientista en 1929, el populismo en la "era" de Getulio Vargas, hasta mediados del siglo XX, con el inicio de los movimientos (sindicatos) agraristas, que tuvieron gran influencia en los movimientos educativos, liderados inicialmente por comunidades con base religiosa y posteriormente con filiales de la izquierda, confluyen con otros movimientos que direccionan y reúnen formas alternativas a la toma del poder o de accionar al interior del Estado como el único fin; mientras en Colombia el desmonte del período del Frente Nacional permitió y configuró una dispersión de movimientos, por efectos de la violencia política, hasta concluir con las bases de grupos que se enfrentan al Estado, los cuales pierden fuerza para presionar fuertemente en la configuración de la Constitución de 1991, como grandes movimientos sociales.

En este sentido, si Brasil presenció el surgimiento del Movimiento de los Trabajadores Rurales Sin Tierra (MST) como figura fundamental de las movilizaciones rurales y de campesinos (Fernandes, Quintanilla, Isasa de Melo y Pozzobon, 2002): "difícilmente dejará de ser consensual la identificación de la emergencia de las luchas sociales en áreas rurales, particularmente aquellas emprendidas por los llamados sin tierra, como las más emblemáticas y distintivas del período" (Santos, Boaventura de Souza, 2002, p. 192). Es necesario considerar que antes de la dictadura militar del poder en 1964 ya habían emergido los primeros sindicatos de trabajadores rurales del país, fruto de la organización de una minoría pobre que hasta ese momento no tuvo condiciones para actuar políticamente. Tales estructuras surgieron durante un período especialmente populista en el cual varios actores, principalmente del sector más progresista de la Iglesia católica, se interesaron por participar de la causa que iniciaba y que daría paso al MST, el cual daría a la lucha agraria un sentido más amplio.

La confluencia del Movimiento Sin Tierra (MST) y otros Movimientos Sociales hizo posible la territorialización o el arraigo desde formas organizativas diferentes, que permitió anteponer el espacio como forma donde se construye colectivamente una nueva organización social (Zibechi, 2003, p. 187). Estos asentamientos y formas de uso del territorio se extendieron a las ciudades, donde las periferias permitieron crear espacios auto-gestionados a nivel comunitario y de subsistencia, con estructuras organizativas autónomas de largo aliento que se convertirían en la figura

8 - Surgidas luego de la creación de las facultades de educación en las universidades 
más importante para los partidos políticos y el Estado.

Estos logros del movimiento se dieron alrededor de la capacidad de cada zona para crear sus propios intelectuales (Zibechi, 2003, p. 186) y así controlar su educación; además se configuró una organización del hogar a partir del papel de la mujer, del trabajo a partir de la naturaleza y lo comunitario, no desde el capitalismo. Ello significó el desarrollo de prácticas de comercialización individual y el estímulo de acciones colectivas, no de huelga o paro, que partían de la afirmación, es decir, las "tomas" incluían una autoafirmación del territorio desde principios que contemplaban otros contenidos y sentidos, distintos de los acostumbrados; la ocupación llevaba a un abandono del anonimato y daba sentido a la vida desde la expresión colectiva. El MST en Brasil se ha convertido en la expresión social más grande de toda América y ha avanzado, desde un planteamiento de reforma agraria, hacia la inclusión de los jóvenes pobres de las grandes ciudades, sin importar que con ello tuviese que enfrentar a los gobiernos de la izquierda brasilera (Zibechi, 2003, p. 31).

Por su parte, en Colombia el contexto de las luchas sociales, de la segunda mitad del siglo XX, ha contado de una u otra forma con la participación permanente del magisterio, ya sea como protagonista o como actor social que interviene desde mecanismos no tan evidentes. A pesar de ello, su presencia en la historiografía sindical colombiana ha sido tangencial, apareciendo someramente en algunas publicaciones académicas. Sin embargo, más allá de su papel historiográfico es necesario considerarle desde su rol como Actor Social Colectivo, reconociendo que sus movilizaciones han sido definitivas para la expansión de la democracia, ya sea desde la configuración de la educación o desde las formas de pensarla, pues su lugar en la triada: alumno - docente - conocimiento propone visiones, no solo de una sociedad democrática, sino de un sistema compartido de creencias y un sentido de pertenencia que contribuye al crecimiento de la sociedad civil (Melucci, 1999, p. 15). Así, y como ocurrió en la mayoría de sociedades latinoamericanas al final del milenio, la construcción de la democracia y la ciudadanía estuvo vinculada a lucha política que se libró en torno a diseños alternativos de la democracia, donde los parámetros estuvieron agenciados por los movimientos sociales y las acciones colectivas en la lucha por los derechos (Escobar y otros, 2001, pp. 6972).

Es en este sentido que el investigador Mauricio Archila presenta la situación política del Frente Nacional, en la década de 1960, como el contexto que da pie a una coalición de partidos tradicionales que se sentían desplazados por el gobierno del General Rojas Pinilla; los liberales tendían a respaldar las condiciones de vida de la clase asalariada, y los conservadores, aliados con la iglesia católica, iban por el poder desde el discurso de estar "en contra de la barbarie". En busca de una respuesta democrática para enfrentar los gobiernos cercanos a una "dictadura civil", reacciona- ron con amplias movilizaciones, mientras se declaraban en paro varios sectores laborales, utilizando este mecanismo como nueva forma de protesta política para reorganizar un sistema en descomposición y generar un programa de reformas que dieran solución a las precarias condiciones de vida y fin a la violencia. Fue en dicho escenario que se dio una de las primeras movilizaciones de maestros: la Marcha del Hambre en 1966, momento de inicio de los repertorios más notorios de los maestros. El período enmarcado en el Frente Nacional se caracterizó:

Por la presencia de guerras permanentes [que facilitó] legitimar formas de control político y social pero sin romper la institucionalidad democrática; justamente en el intento de superar la polarización política que había generado tanta violencia se da el pacto bipartidista logrando control civil y estabilidad macroeconómica, pero se generó por otro lado la exclusión de toda forma de oposición, privatización, situaciones de desplazamiento, el clientelismo de los partidos tradicionales, autonomía de parte de los militares en el manejo de orden público, el relativo abandono de lo social, es en ese contexto en que se da la violencia guerrillera y se debilita el bipartidismo, surge una nueva crisis política (Archila, 2002), p. 14).

La Marcha del hambre se llevó a cabo durante una coyuntura política en la que el bipartidismo liberalconservador cerró todo espacio a la lucha de los trabajadores y sectores populares. De ahí que en este período se asista a la aparición de grandes movimientos sociales y de insurgencias armadas cuyos orígenes se remontaban a otras esferas de acción, como las guerrillas liberales, de allí surgen grupos como las Fuerzas Armadas Revolucionarias de Colombia (FARC) (1964); el Ejército de Liberación Nacional (ELN) (1965); el Ejército Popular de Liberación (EPL) (1967); el Movimiento 19 de Abril (M-19) (1974), y el Movimiento Armando Quintín Lame (MAQL) (1984) entre otros. Estos actores también ayudaron a impulsar movilizaciones de protesta y/o de huelga.

Para Múnera (1988), entre 1958 y 1966, pese a la dominación y represión de los empresarios, la corrupción de los dirigentes y el incumplimiento de las convenciones colectivas, las organizaciones sindicales atravesaron por un momento importante de reconstitución: "La legislación entre 1958 y 1966 respaldó la recomposición del sindicalismo, estableciendo garantías mínimas para las organizaciones obreras con el fin de obtener un reconocimiento institucional de un sindicato en contra de las disposiciones de la OIT" (Cárdenas, 1990, pp. 60-63). Esto se hizo evidente en casos como el de la constitución de la CSTC, en sintonía con del Partido Comunista Colombiano ( $\mathrm{PCC}$ ), que tuvo como objetivo establecer alianza con las dos centrales la CTC y la UTC para unificar las acciones del sindicalismo colombiano (Múnera, R., 1988, p. 366).

Esta lucha por las mínimas garantías para las acciones colectivas de los trabajadores propició cambios importantes en el sindicalismo colombiano, a causa del deterioro de las políticas de desarrollo económico del país, que generó la caída de ingresos de sectores 
populares y el aumento de impuestos, lo cual obligó a un replanteamiento y distanciamiento de las centrales tradicionales de corte patronal como la CTC y la UTC, que se movilizaron también inicialmente para contrarrestar la política económica del gobierno y deslegitimar las relaciones laborales con el Estado; tal proceso les permitió al magisterio asumirse en el espacio donde se desarrolla el sindicalismo de izquierda, y desde donde centraron sus acciones en la huelga, las tomas de fábricas, las operaciones tortuga, los bloqueos de las carreteras o el enfrentamiento con la fuerza pública (Múnera, R., 1988).

Los actores sociales que participaron de estas luchas utilizan el sentido ambiguo de movimientos cívicos para designar las reivindicaciones en torno a los derechos, llamados "del pueblo". Y por otro lado fundaron la imagen de los sindicatos como punto de apoyo de los dirigentes y recurso indispensable para el ascenso en la estructura sindical (Múnera, R., 1988). Los trabajadores sindicalizados entre los cuales se vinculan el magisterio se acogieron la ideología y el discurso revolucionario del momento, que pasó a ser símbolo instintivo de la izquierda social, praxis que les aportaba los elementos para identificarse como clase obrera y como eje de las organizaciones de izquierda en tanto grandes actores sociales con capacidad de decisión frente a las élites dominantes. Es de agregar que esta beligerancia de izquierda fue importante para direccionar las movilizaciones obreras, quebrando la sumisión política y social característica de las relaciones laborales de Colombia (Múnera, R., 1988, p. 371).

Así, durante la década del 1960-1970, Colombia vivía un período de gran hostilidad contra la sindicalización, debido al miedo que existía hacía el sindicalismo radical y politizado, mas sin embargo prevalecía la política paternalista de la empresa y el régimen de personal de los mandos medios de producción, lo que oponía a la sindicalización, viéndose el poder y su política de estos amenazados por el "favoritismo" por un sindicato que establecería normas impersonales, formales y generales (Múnera, R., 1988, pp. 155-156).

La ampliación de la protesta urbana, con nuevas prácticas políticas y sociales, sumada a las luchas de las comunidades campesinas y el uso de las luchas directas, así como la corrupción y la burocracia, la desviación de recursos públicos hacia fines privados en función del clientelismo transaccional, generaron el desorden formal del Estado que contribuyó a la eficacia política respondida con un uso clientelista de recursos o la cooptación política (Leal y Dávila, p.330, citados en Múnera 1988, p. 405). Así, desde 1964 el sindicalismo colombiano se divide en dos grandes campos: los organismos tradicionales, respaldados por el gobierno, y los de oposición, liderados por la central de trabajadores CSTC, orientada por el PCC. El movimiento sindical fue visto como parte de la estrategia militar de la insurgencia para llegar a la toma del poder en el contexto de la doctrina de Seguridad Nacional, cuyo eje de conflicto era la hibridación económica de Colombia y su absorción de los experimentos modernizadores de dichos sectores, desatando con gran violencia las propuestas basadas en definir otro tipo de desarrollo agrario e industrial para el país, deteniendo las políticas públicas que determinarían la economía hasta los años 1990 (Múnera, R., 1988, p. 339).

Por otro lado, entre 1965 y 1980 se amplió la acción de los trabajadores del sector público, entre ellos el magisterio, que vinculándose a la central contestaría CSTC, generó junto al sindicalismo independiente una gran cantidad de agitación y de presión política. Mientras tanto las centrales ligadas al gobierno y a los empresarios (UTC, CTC y CGT) terminaron asumiendo una actitud conciliadora que significó una gran corrupción de sus dirigentes sindicales (de corte liberal y conservador), llevándoles a la buscar intereses particulares, en un proceso de descomposición que presenció la caída de la tasa de sindicalización y la pérdida de legitimidad de este gran sector del movimiento obrero, dificultando además la manera de hacer frente a las acciones del gobierno y los empresarios. Estas centrales sindicales no pudieron transformarse en un movimiento social alternativo y se mantuvieron subordinadas a los partidos tradicionales, al Estado o a la iglesia católica.

De igual forma, las organizaciones campesinas y los movimientos cívicos no se articularon definitivamente con el movimiento sindical radical, limitándose a participar esporádicamente, en algunos casos, desde la diversidad y heterogeneidad política de los sindicatos y las federaciones del magisterio como Fecode. Así, el magisterio fue víctima de la intimidación y persecución de la violencia estatal, mientras estaba también imposibilitado para incidir en la política pública educativa, pues fue sometido a políticas de control policial, sujeción irrestricta a los designios del Estado y a la clientelización burocrática del sector.

Desde una perspectiva conclusiva las difíciles condiciones económicas para el profesorado; a inicios de los años 1960 donde la inestabilidad laboral era palpable $y$, junto a factores como la privatización de la educación y la falta de la nacionalización de la educación pública, llevó al magisterio a tomar una posición de resistencia, organizándose y movilizándose en busca de reivindicaciones salariales y de derechos de la profesión que incluían la necesidad de reconocimiento. Estas movilizaciones empiezan a ser visibles y apoyadas desde la "Marcha del Hambre", realizada por maestros del Magdalena en 1966 (Archila, 2012, pp. 169-175). En estas condiciones, las políticas educativas de los gobiernos nacionales que asumían una visión "desarrollista" fueron contrarrestadas aisladamente por el movimiento estudiantil y del magisterio, llevando al sector educativo a ser el escenario de una disputa ideológica y política en torno a la orientación y fines de la educación (Guardiola, 2013).

El magisterio fue llevado a apelar a los paros, huelgas y protestas permanentes que se expresaron sin vínculos fuertes con otros sectores de las capas medias, el 
movimiento estuvo mediado por una participación que no podía ser abierta, siempre limitado o por las represalias del gobierno, que sancionaba o despedía del trabajo a los profesores o por una subordinación ideológica de los sectores radicalizados de la izquierda. Para la década de 1970 sus protestas por la implantación del modelo desarrollista para la educación, definido como de la tecnología educativa, evidenciaron que la influencia del Partido Comunista era muy fuerte en la mayor parte del Magisterio, y en menor medida por un grupo liberal independiente dirigido por Adalberto Carvajal, que les redujo su acción al logro de un estatuto docente y a una ley general de la educación que garantizara la sostenibilidad, la calidad de la educación pública y protegiera la profesión.

Es en este contexto que Alexis Pinilla (2013) expresa, siguiendo a Abel Rodríguez, la configuración de tres etapas de la lucha del magisterio hasta 1990: la de los "descamisados", inicio de Fecode, obedeció a las precarias condiciones de vida de los maestros hasta inicios de 1970: la de "radicalización", desde 1975, cuando la presidencia de Fecode es asumida por un militante de izquierda, llegando al Estatuto docente; y la de "consolidación", desde 1982, que logra un movimiento pedagógico mientras el magisterio entra en una etapa de mediación a la vez que de presión por medio de las protestas.

Desde estos planteamientos, es posible el inicio de una comparación trasnacional, de donde resulta necesario llegar a interrogantes que ubiquen en la dinámica de las movilizaciones para Colombia, sus consecuencias y desarrollos: ¿Por qué en Colombia estos movimientos no tuvieron el alcance que lograron en Brasil?; ¿por qué no se expresaron en torno a la identidad y las formas organizativas colectivas?; ¿por qué se truncaron las posibilidades de crear nuevas relaciones sociales al interior de los territorios?; ¿si la lucha permitió la posibilidad de expresar formas distintas de autogestión, por qué no se sostienen en el tiempo y se expanden gracias a ella?

\section{Referencias}

Archila, M. (2002). 25 años de Luchas Sociales en Colombia. Bogotá: CINEP.

Archila, M. (2012). Violencia contra el Sindicalismo. Bogotá: Universidad Pedagógica.

Bloch, M. (1995). Historia e Historiadores. Madrid: Akal.

Castells, M. (1998). El poder de la identidad. Madrid: Alianza.
Elliott, A. (1992). Psicoanálisis, ideología y sociedades modernas. Teoria social pos-lacaniana. En Elliott, A. Teoria social $y$ psicoanálisis en transición. Sujeto y sociedad de Freud a Kristeva. Buenos Aires: Amorrortu.

Escobar, A. (2011). América Latina en una encrucijada: ¿Modernizaciones alternativas, postliberalismo o posdesarrollo? Controversia.

Escobar, A. Alvarez, S. y Dagnino, E. (2001) Politica Cultural y Cultura politica. Una mirada sobre los movimientos sociales latinoamericanos. Editorial taurus. Bogotá, Colombia.

Eyerman, R. (1998). La praxis cultural de los movimientos sociales. Los movimientos sociales. Transformaciones politicas y cambio cultural Madrid: Trotta.

Fernandes, A., Quintanilla, G., Isasa de Melo, M., y Pozzobon, R. (2002). Consideraciones sobre los movimientos sociales y la participación popular en Brasil. Nueva Sociedad.

Gadotti, M. (2001). Cruzando fronteras. Lecciones de Freire. Revista Cuadernos Pedagógicos de la Escuela.

Gadotti, M. (2003). Lecciones de Freire. Cruzando Fronteras.

García Linera, A. (2009). La potencia plebeya. Acción colectiva e identidades indigenas, obreras y populares en Bolivia. Buenos Aires: CLACSO-Siglo del Hombre.

Guardiola, I. (2013). La dimensión histórica y política de la Marcha del Hambre. Zona Cero.

Klimke, M., y Joachim, S. (2008). 1968 in Europe. A history of protest and activism, 1956-1977. New York: Palgrave Macmillan.

Kocka, J. (2003). Comparison and Beyond. History and Theory.

Lenharo, A. (1986). Sacralizacao da Politica. Campinas: papirus.

McAdam, D., Tarrow, S., y Tilly, C. (2001). Dinámica de la contienda politica. Barcelona: Cambrige University Press.

Melucci, A. (1999). Acción colectiva, vida cotidiana y democracia. México: El Colegio de México.

Múnera Ruiz, L. (2012). Movimientos sociales en América Latina: entre la forma-comunidad y la forma-Estado. ¿Otros mundos posibles? Crisis, gobiernos progresistas, alternativas de sociedad. Medellín: Universidad Nacional de Colombia.

Múnera, R. (1988). Movimiento Sindical: Fragmentación y Articulaciones.

Murillo de Carvalho, J. (1990). A formacao das almas. Oo imaginario da Republica no Brasil. Sáo Paulo: Companhia das Letras.

Piñeiro, D. E. (2004). En Busca de la identidad. La acción colectiva en los conflictos agrarios de América Latina. Buenos Aires: Libros Clacso.

Rivas, A. (1998). El análisis de los marcos: una metodología para el estudio de los movimientos sociales. En Ibarra, P., y Tejerina, B. Los movimientos sociales. Transformaciones politicas y cambio cultural. Madrid: Trotta.

Seigel, M. (2009). Uneven encounters: Making race and nation in Brazil and the United States. Duke: Ebrary GC

Skocpol, T. (1984). Los Estados y las revoluciones sociales. Un análisis comparativo de Francia, Rusia y China. México: Fondo de Cultura Económica.

Spina, F. M. (1987). Tenentismo e política. Tenentismo e camadas medias urbanas na crise da primera república. Sao Paulo: Paz e Terra.

Tarrow, S. (1997). El poder en movimiento. Madrid: Alianza.

Thompson, E. P. (1995). Costumbres en Común. Barcelona: Crítica.

Tilly, C., y Wood, L. (2010). Los movimientos Sociales, 1768-2008. Desde sus origenes a Facebook. Barcelona: Crítica.

Touraine, A. (1987). El regreso del actor. Buenos Aires: Eudeba.

Santos, Boaventura de Souza (2002). Produzir para viver: Os caminhos da produção nâo capitalista, Río de Janeiro: Civilização Brasileira, p. 192.

Zibechi, R. (2003). Los movimientos sociales latinoamericanos tendencias y desafíos. Buenos Aires: OSAL Observatorio Social de América Latina-Clacso.

Zibechi, R. (2006). Dispersar el poder. Los movimientos como poderes antiestatales. Buenos Aires: Tinta Limón-Ediciones Desde Abajo. 